\title{
Futebol como simulacro: Tipp-Kick, um jogo alemão
}

\author{
Football as simulacrum: \\ Tipp-Kick, a German game
}

Elcio Loureiro Cornelsen

Universidade Federal de Minas Gerais (UFMG), Belo Horizonte/Brasil

Doutor em Germanística, Freie Universität Berlin

emcor@uol.com.br

RESumo: Nossa contribuição visa a uma reflexão sobre um jogo em especial, o TippKick, criado na Alemanha, na década de 1920, como simulacro do futebol. Em termos teóricos, orientar-nos-emos pelas noções de "ludicidade", "jogo" e "representação" propostas pelo historiador e linguista holandês Johan Huizinga, bem como pela noção de "simulacro", conforme definida pelo sociólogo francês Roger Caillois.

PalavRAS-ChaVE: Futebol; Jogo; Simulacro; Homo Ludens; Tipp-Kick.

ABSTRACT: Our contribution aims at a reflection on a particular game, the TippKick, created in Germany in the 1920s, as a simulacrum of football. In theoretical terms, we will be guided by the notions of "playfulness", "game" and "representation" proposed by the Dutch historian and linguist Johan Huizinga, as well as the notion of "simulacrum", as defined by the French sociologist Roger Caillois.

KEYWORDS: Football; Game; Simulacrum; Homo Ludens; Tipp-Kick. 


\section{INTRODUÇÃO: FUTEBOL, LUDICIDADE E SIMULACRO}

Na obra clássica Homo Ludens: o jogo como elemento da cultura (1938; 2010), o historiador e linguista holandês Johan Huizinga postula que o lúdico seria um componente da própria natureza humana. Basicamente, o ser humano apresentaria três propriedades fundamentais: o raciocínio (o Homo Sapiens), a engenhosidade prática (o Homo Faber), e a ludicidade (o Homo Ludens). ${ }^{1}$

Portanto, de maneira geral, enquanto fenômeno cultural, o jogo seria a concretização da ludicidade na sociedade. De acordo com Huizinga, o jogo “[u]ltrapassa os limites da atividade puramente física ou biológica. É uma função 'significante', isto é, encerra um determinado sentido". ${ }^{2}$ Uma noção central no estudo do historiador holandês é, justamente, a de conceber o jogo como "forma significante"3 que desempenha uma função social.

Assim postulado, o jogo apresentaria duas características fundamentais: por um lado, "o fato de ser livre, de ele próprio ser liberdade"; por outro, "o jogo não é 'vida corrente' nem vida 'real'. Pelo contrário, trata-se de uma evasão da vida 'real' para uma esfera temporária de atividade com orientação própria". ${ }^{4}$ Sua função seria definida por dois aspectos fundamentais: “uma luta 'por' alguma coisa ou a representação 'de' alguma coisa”. ${ }^{5}$

Para nossas conjecturas, a noção de jogo com função de "representação", proposta por Huizinga, enquanto "'reapresentação' do acontecimento", 6 se torna cara. Se pensarmos em uma partida de futebol para além da sua própria ludicidade, como acontecimento que é passível de inspirar outras formas de jogo, chegamos à noção de "simulacro" ao abordar o conceito de "mimicry", proposta pelo sociólogo francês Roger Caillois, um seguidor teórico do historiador holandês: "o prazer é o de ser um outro ou o de se passar por outro". ${ }^{7}$

\footnotetext{
${ }^{1}$ HUIZINGA. Homo Ludens, p. 1.

2 HUIZINGA. Homo Ludens, p. 3-4.

${ }^{3}$ HUIZINGA. Homo Ludens, p. 6.

${ }^{4}$ HUIZINGA. Homo Ludens, p. 11.

${ }^{5}$ HUIZINGA. Homo Ludens, p. 16.

${ }^{6}$ HUIZINGA. Homo Ludens, p. 18.

${ }^{7}$ CAILLOIS. Os jogos e os homens, p. 42.
} 
Partindo de tal afirmativa, podemos encontrar nas mais diversas sociedades vários exemplos de jogos que não só simulam acontecimentos - pensemos, aqui, nos jogos de guerra, com tradição milenar -, como também aqueles que simulam outras atividades igualmente lúdicas. 0 futebol é uma delas. Não é por acaso que, por ser uma das modalidades esportivas e de lazer mais difundidas no planeta, o futebol tenha inspirado a criação de vários jogos ao longo do século XX, autênticos simulacros com especificidades materiais e regras próprias.

São vários os jogos que, enquanto simulacros, se originaram do futebol. No contexto brasileiro, por exemplo, alguns se popularizaram mais do que outros. As modalidades de futebol de mesa são as mais populares, com destaque para o Totó ou Pebolim, ${ }^{8}$ cujas raízes remontariam à Espanha ou à Alemanha dos anos 1930, e também o futebol de botão, que pode ser considerado como jogo genuinamente brasileiro que simula o futebol, criado em 1930 por Geraldo Décourt. ${ }^{9}$ E também o Subbuteo, mais conhecido no Brasil como Pelebol e original da Inglaterra, teve sua fase áurea nos anos 1970 e 1980.10

Assim como no Brasil, alguns jogos fizeram e fazem sucesso como simulacros do futebol. Tanto o Pebolim quanto o Subbuteo possuem um grande número de aficionados na terra dos tetracampeões mundiais de futebol para homens e das bicampeãs mundiais de futebol para mulheres. Todavia, o futebol de botão não é praticado entre os alemães (por isso, é sempre um bom presente como um jogo "exótico" oriundo do "país do futebol"). Mas o principal dos jogos que simulam o futebol, o mais praticado e genuinamente alemão, é o Tipp-Kick, nome que podemos traduzir - ou "transluciferar", como diria Haroldo de Campos, de um modo até insatisfatório, por "toca-chuta". Deixemos, pois, ser Tipp-Kick.

\footnotetext{
${ }^{8}$ Para informações sobre história e prática do Pebolim, ver GOMES. Pebolim, Totó, Fla-Flu ou Pacau? Um breve histórico do campo esportivo no Brasil, s/p.

${ }_{9}^{9}$ Para maiores informações, ver ROLIM. Futebol de Mesa: brincadeira que virou esporte, s/p.

${ }^{10}$ Para informações sobre a história e a prática do Subbuteo, ver CORNELSEN. O futebol e seus simulacros no reino da ludicidade - Subbuteo, s/p.
} 
FuLiA / UFMG - Futebol como simulacro:Tipp-Kick, um jogo alemão

\section{TIPP-KICK - UM JOGO GENUINAMENTE ALEMÃO11}

A criação do Tipp-Kick remonta à década de 1920. Segundo consta, seu criador fora o alemão Carl Mayer, original de Stuttgart, que, em 1921, procurou simular o futebol através de um jogo em que pequenas figuras de metal representando jogadores contivessem uma das pernas móvel, a direita, e, através de acionamento de um botão na cabeça, pudessem chutar uma bola, ou melhor, um dadinho. A posição em que o dado caia determinava de quem era a posse de bola. ${ }^{12}$

Todavia, a fabricação de mobílias, atividade principal de Carl Mayer, lhe tomava muito tempo, de modo que ele não cogitara produzir e lançar no mercado o novo jogo que criara mais como um hobby, para entretenimento próprio. Porém, no mesmo ano, alguém se interessara pela nova criação após jogar e ficar fascinado pelo Tipp-Kick: Edwin Mieg. De imediato, este se associara a Carl Mayer, que patenteara o jogo em 15 de setembro de 1923, e se tornara no ano seguinte fabricante de brinquedos. Interessante é que no Registro de Patente no 387569, expedido em 05 de janeiro de 1924, não consta o nome Tipp-Kick, mas sim, literalmente, "Jogo de futebol de tabuleiro" (Fußballbrettspiel). ${ }^{13}$ E o Registro já trazia uma modificação significativa: a bola não era mais improvisada com dadinho, mas sim uma esfera angular de cortiça com duas metades e 12 cantos, cada uma de uma cor correspondente a um dos dois jogadores, e cujo rolamento era limitado por seu formato.

Assim, se iniciou a produção de um dos jogos mais populares da Alemanha. No começo, as figuras representando os jogadores eram confeccionadas de lata, que lhes proporcionava pouca estabilidade. Edwin Mieg, entretanto, solucionou o problema, confeccionando as figuras com chumbo. 0 fabricante apresentou a novidade na Feira de Leipzig, em 1926. Embora não tivesse condições de alugar um estande na Feira, ele improvisou uma prateleira com uma escada em frente a

\footnotetext{
${ }^{11}$ As informações que constam desta seção têm por fonte a obra Das große Tipp-Kick-Buch (2008), de Katrin Höfer e Peter Hesse, e o estudo de Simon Winzer, Das professionelle TippKick: Ein Spiel im Spannungsfeld zwischen Hobby und sportlicher Anerkennung (2016). Além dessas obras, alguns artigos publicados em sites e blogs, relacionados nas Referências Bibliográficas, serviram, igualmente, de fonte para a construção do panorama histórico sobre o jogo Tipp-Kick.

${ }_{12}$ MEINERT. Tipp-Kick: Kult aus Schwenningen, s/p.

${ }^{13}$ HÖFER; HESSE. Das Tipp-Kick-Buch, p. 14.
} 
um dos pavilhões, onde expôs seus jogadores e goleiros. Assim, Mieg atraiu tanto a atenção dos visitantes que teve de ser removido dali com seu estande improvisado. Sem se dar por vencido, mudou de pavilhão e pôde comercializar o novo jogo. Aliás, os goleiros ainda não possuíam a mobilidade de versões posteriores e eram representados em posição de defesa, como em um lance de pênalti, e eram fixados a uma haste, através da qual poderiam ser movimentados. ${ }^{14}$

Levaria algum tempo até que Tipp-Kick se tornasse uma verdadeira coqueluche. Nos primeiros anos, a produção cresceu constantemente, e em 1938 o empreendimento se expandiu, de modo que a firma Mieg, com sede na cidade de Villingen-Schwenningen, no Estado de Baden-Württemberg, passou a ter uma fábrica própria para dar conta da demanda pelo jogo. ${ }^{15} \mathrm{O}$ verdadeiro boom só foi atingido nos anos 1950, mais precisamente em 1954, ano em que a Alemanha Ocidental, pela primeira vez, se tornara campeã mundial de futebol, no chamado "Milagre de Berna" (Wunder von Bern), como entraria para a História a vitória épica da seleção comandada pelo capitão Fritz Walter contra o fortíssimo esquadrão húngaro comandado por Ferenc Puskas, pelo placar de 3 × $2 .{ }^{16}$

No contexto do Mundial de 1954, a cifra de jogos produzidos pela Mieg atingiu a marca de 180.000 unidades. Certamente, em termos de marketing, a conquista do título mundial representou um impulso significativo para a consolidação do Tipp-Kick como o jogo de futebol de mesa preferido entre os alemães. ${ }^{17}$ Todavia, Edwin Mieg não conheceu essa fase áurea do jogo que aperfeiçoara e auxiliara a popularizar, pois falecera em 1948. Coube aos herdeiros, os filhos Peter e Hansjörg Mieg, assumirem o empreendimento. Com a morte de Peter em 1991, seu filho Mathias assumiu a direção da empresa juntamente com o tio Hansjörg Mieg, o qual foi substituído, posteriormente, por seu filho Jochen. Assim, os primos Mathias e Jochen Mieg dirigem atualmente esse empreendimento familiar que se aproxima de completar 100 anos.

\footnotetext{
${ }^{14}$ WINZER. Das professionelle Tipp-Kick, p. 2.

${ }^{15}$ WINZER. Das professionelle Tipp-Kick, p. 2.

16 Sobre o "Milagre de Berna", ver CORNELSEN. Sentimento e política no futebol alemão construções da "nação" em 1990 e 2006, p. 84-85.

${ }^{17}$ MEINERT. Tipp-Kick: Kult aus Schwenningen, s/p.
} 
O sucesso do Tipp-Kick está intimamente associado com os aperfeiçoamentos que o jogo sofreu ao longo do tempo, tanto do campo de jogo, quanto das figuras e demais acessórios, no sentido de elevar sua qualidade em termos de jogabilidade. 0 novo modelo do goleiro, por exemplo, designado de "Toni", em homenagem a Toni Turek, o lendário goleiro alemão da conquista de 1954, obteve maior mobilidade através de uma pequena caixa atrelada à haste, em que dois botões poderiam ser acionados, fazendo com que a figura caísse para um lado ou para o outro, ou mesmo se inclinasse para frente. ${ }^{18}$ Além disso, a posição do goleiro não era mais aquela como se estivesse preparado para um lance de penalidade máxima, mas sim em posição de defesa com os braços erguidos em salto, o que aumentou sua envergadura.

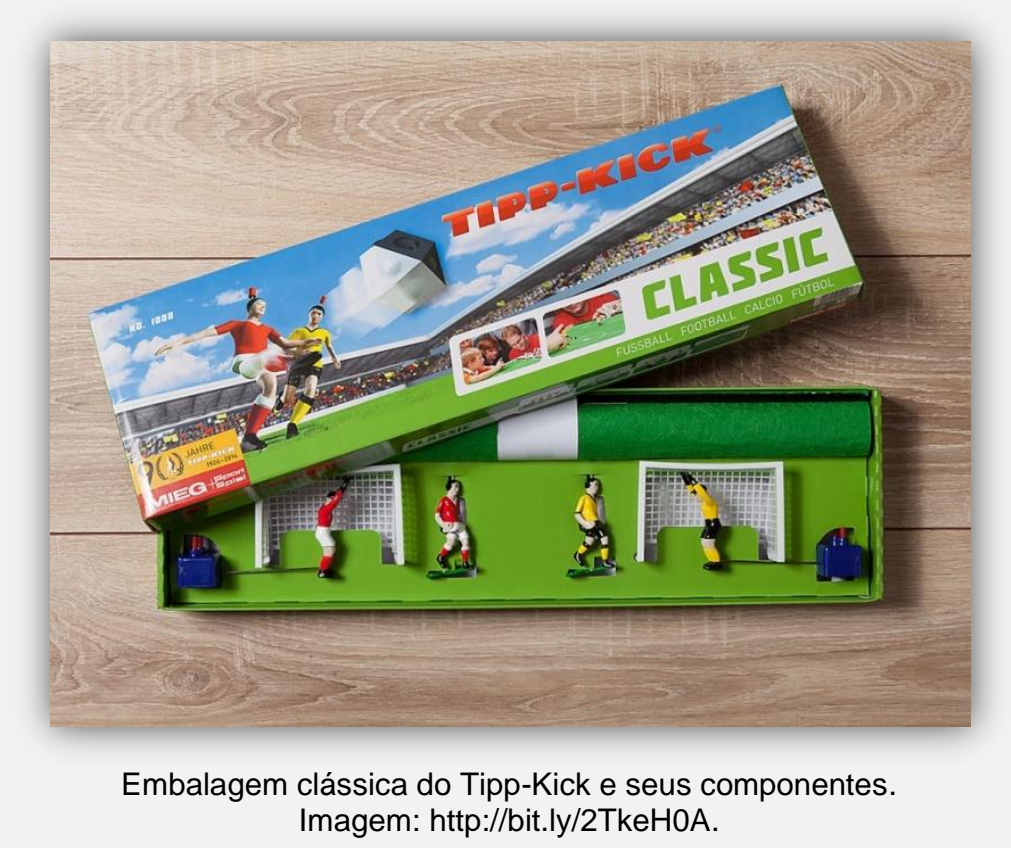

Nas décadas seguintes, outras modificações foram processadas no TippKick: embora as regras do jogo, ${ }^{19}$ em essência, tenham se mantido inalteradas, as metas e as bolas passaram a ser confeccionadas de plástico, em substituição às traves de metal e às bolas de cortiça, as dimensões do campo de jogo foram ampliadas, os jogadores passaram a ser fabricados de zinco em substituição ao chumbo, e a fábrica Mieg produziu os primeiros cronômetros para marcação do

\footnotetext{
${ }_{18}^{18}$ WINZER. Das professionelle Tipp-Kick, p. 2.

${ }^{19}$ As regras do jogo Tipp-Kick serão apresentadas brevemente em outra seção do artigo. Para informações completas, ver TIPP-KICK SPIELREGELN, 01 ago. 2017, p. 1-17.
} 
tempo das partidas. A expansão da produção frente à demanda de mercado se mantinha contínua, de modo que a empresa precisou construir uma nova fábrica em 1963.20

Mais uma vez, assim como ocorrera em 1954, o calendário esportivo parecia estar sincronizado às metas de expansão dos Mieg: 1963 é o ano em que foi criada a Bundesliga, o campeonato alemão de futebol, até então disputado regionalmente. Pela primeira vez, as figuras do Tipp-Kick foram pintadas manualmente com as cores dos principais clubes alemães que disputavam a Liga. Em 1967, um ano após a polêmica derrota da seleção da Alemanha Ocidental na final do Mundial contra a Inglaterra, a firma Mieg fechou um contrato publicitário com Gerd Müller, centroavante e um dos maiores artilheiros da seleção e do Bayern de Munique, para que sua imagem fosse estampada na embalagem do Tipp-Kick. ${ }^{21}$

Por sua vez, em 1974, ano em que a Alemanha Ocidental sediou a Copa do Mundo pela primeira vez, no auge da Guerra Fria, a firma Mieg produziu figuras nas cores das seleções que disputariam o torneio. Um dos objetivos era possibilitar uma expansão ainda maior da popularidade do Tipp-Kick, para além das fronteiras alemãs. Nessa mesma época, aumentou-se ainda mais a estabilidade dos jogadores através da inserção de um pequeno cilindro de chumbo em sua base. Em 1978, foram lançadas traves contendo redes, e em 1982, além dos movimentos laterais por acionamento de botões, o goleiro podia mover-se também tombando para frente. ${ }^{22}$

Outro ponto alto na trajetória da firma Mieg e de seu produto foi atingido com a Copa do Mundo de 2006, quando a Alemanha, desta feita já reunificada, sediou pela segunda vez o torneio. Segundo Anne Seith, em artigo publicado na revista Der Spiegel, a firma vendeu mais de 200.000 unidades do Tipp-Kick, superando a marca recorde de $1954 .^{23}$ Nesse contexto, a empresa empreendeu uma intensa campanha publicitária que tornou Tipp-Kick ainda mais popular nos países vizinhos de língua alemã - a Suíça e a Áustria. Todavia, o mesmo sucesso ainda não foi atingido em outros países europeus. Além disso, diante dos desafios econômicos, e do fato de ser uma das menores empresas de fabricação de

\footnotetext{
${ }^{20}$ WINZER. Das professionelle Tipp-Kick, p. 2.

${ }^{21}$ WINZER. Das professionelle Tipp-Kick, p. 2.

${ }^{22}$ WINZER. Das professionelle Tipp-Kick, p. 2.

${ }^{23}$ SEITH. Tipp-Kick-Kult: WM auf dem Küchentisch, s/p.
} 
brinquedos da Alemanha, a Mieg se viu diante da necessidade de transferir a produção para outros locais a fim de baratear os custos. Desde 2006, a firma realiza parte de sua produção na China, principalmente para abastecer os mercados asiático e sul-americano.

No contexto da Copa do Mundo de 2018, mais uma vez, aproveitando o calendário esportivo, a firma Mieg realizou uma grande estratégia de marketing no intuito de aumentar ainda mais a produção e as vendas. Um artigo publicado no principal jornal alemão, o Frankfurter Allgemeine Zeitung (FAZ), em 27 de junho de 2018, ressaltou tal ação no próprio título: "Die WM rettet Tipp-Kick" ("O Mundial salva o Tipp-Kick"). ${ }^{24}$ Segundo um de seus presidentes, Mathias Mieg, nos primeiros meses do ano a firma já havia superado números anuais entre 120.000 e 140.000 unidades. As 32 seleções que disputariam o torneio foram contempladas nessa nova edição, em que os jogadores de linha foram pintados com as cores de suas camisas. Segundo Peer Meinert, a firma produziu 10.000 unidades com camisas da seleção alemã, enquanto seleções como a do Iran ou a de Senegal tiveram uma tiragem bem reduzida, de 5 unidades. ${ }^{25}$

Todavia, além do Mundial da Rússia, a elevação da demanda deveu-se também a uma estratégia de marketing produzida em conjunto com uma rede de supermercados, que ofereceu como brinde uma figura de jogador de linha do Tipp Kick a cada cliente que fizesse compras superiores a 40 Euros, bem como colocou os produtos da Mieg à venda em suas prateleiras. As figuras para essa ação foram produzidas na China. Porém, apenas o trabalho de fundição foi executado no país asiático, pois, como de costume, o trabalho de pintura das figuras permaneceu sendo feito a mão na sede, em Villingen-Schwenningen. ${ }^{26}$

Assim como no Brasil e em outras partes do mundo, o Tipp-Kick enfrenta a concorrência de outros jogos que procuram simular o futebol, sobretudo para o Subbuteo, muito difundido e praticado na Alemanha e em outros países da Europa, mas também para outro jogo desenvolvido pela Playmobil, marca líder em produção de brinquedos no país, além da indústria de videogames de última

\footnotetext{
${ }^{24}$ DIE WM RETTET TIPP-KICK, s/p.

${ }^{25}$ MEINERT. Tipp-Kick: Kult aus Schwenningen, s/p.

${ }^{26}$ DIE WM RETTET TIPP-KICK, s/p.
} 
geração. Todavia, como bem aponta Peer Meinert, o Tipp-Kick ainda resiste heroicamente à concorrência dos videogames, sobretudo em anos de Copa do Mundo e de Eurocopa, com um aumento de produção em torno de 30 a 40\%, mesmo que possa parecer algo obsoleto e ultrapassado que remonta a um passado remoto. ${ }^{27}$ Trata-se de um produto praticamente artesanal, seus jogadores são montados e pintados à mão.

Fato é que o Tipp-Kick se aproxima de seu centenário e ainda fascina muita gente na Alemanha. E as perspectivas para os primos Mathias e Jochen Mieg e sua firma são promissoras: 2024, ano do centenário, será ano de Eurocopa, e a Alemanha sediará o torneio. Portanto, será um ano perfeito, pelo menos, para os fabricantes do Tipp-Kick.

\section{TIPP-KICK: PARA ALÉM DE UM HOBBY, UM JOGO PROFISSIONAL}

Em termos históricos, segundo Simon Winzer, o primeiro clube de Tipp-Kick da Alemanha para prática profissional fora fundado na primavera de 1938 , um ano antes da eclosão da Segunda Guerra Mundial, por cinco jovens em idade entre $11 \mathrm{e}$ 14 anos: o TFG' 38 Hildesheim. Estes modificaram algumas regras e construíram um campo de jogo emoldurado, de modo a possibilitar uma superfície estável, na proporção de 1:100 em relação às dimensões médias de um campo de futebol, medida essa que vigora até os dias atuais. A partir dos anos 1960, foram construídas mesas de jogo e começaram as disputas nas primeiras Ligas em âmbito nacional e regional. Assim, surgiu uma organização para regulamentar a prática do Tipp-Kick na Alemanha - a Associação Alemã de Tipp-Kick (Deutscher Tipp-Kick Verband; DTKV). ${ }^{28}$

Em 1959, ocorreu a primeira edição do Campeonato Alemão de Tipp-Kick, na categoria individual, que, inicialmente, passou a ser realizado a cada dois anos, e que se mantém como o torneio mais importante do calendário esportivo das Ligas de Tipp-Kick. Desde a década de 1960, com o passar dos anos e o crescimento do interesse pela prática profissional, novas agremiações para a prática do Tipp-Kick

\footnotetext{
${ }^{27}$ MEINERT. Tipp-Kick: Kult aus Schwenningen, s/p.

${ }^{28}$ WINZER. Das professionelle Tipp-Kick, p. 2.
} 
foram fundadas. Além disso, as disputas despertaram também o interesse da mídia. Na temporada 2010-2011, a Associação Alemã de Tipp-Kick registrou um número de 649 agremiações afiliadas, o que demonstra a amplitude da prática desse jogo como modalidade profissional. ${ }^{29}$

Segundo Simon Winzer, há algumas diferenças entre o Tipp-Kick praticado como hobby e o Tipp-Kick praticado profissionalmente, que vão além dos tipos de superfície em que são praticados: enquanto o Tipp-Kick comercializado para o público em geral possui um campo emborrachado ou de feltro, enrolado feito tapete, que pode ser estendido sobre qualquer superfície plana, por exemplo, sobre uma mesa de cozinha, o Tipp-Kick profissional é jogado em mesas específicas, revestidas de feltro, com dimensão igualmente específica, e com emolduramento, e as traves de ferro são parafusadas à superfície. As dimensões do campo de jogo variam entre $1,23 \mathrm{~m}$ e $1,26 \mathrm{~m}$ de comprimento por $0,80 \mathrm{~m}$ e $0,83 \mathrm{~m}$ de largura, e a dimensão do círculo central e das áreas também pode variar. Para a prática profissional, tais produtos são licenciados e podem ser adquiridos diretamente junto à DTKV. 30

Além disso, na prática profissional, cada time conta com um goleiro e vários jogadores de linha, sendo que cada um exerce funções distintas, enquanto que um jogador que joga o Tipp-Kick como hobby possui apenas um jogador de linha para todas as funções. ${ }^{31} \mathrm{~A}$ diferença entre os jogadores de linha na prática profissional está na precisão de seus toques e chutes, garantida pela confecção precisa e milimétrica de suas pernas móveis em aço nobre. Assim, um jogador de Tipp-Kick profissional pode lançar mão de até 05 jogadores diferentes no decorrer da partida para executar as funções desejadas (chute forte baixo, chute por cobertura, chute com efeito etc.).

Todavia, há ainda outras diferenças entre o Tipp-Kick disponibilizado no mercado para o público em geral e aquele praticado profissionalmente: enquanto que além de jogadores de linha, goleiros, traves e bolinhas a embalagem do jogo da Mieg traz também um pequeno folheto de 05 páginas contendo as regras, a

\footnotetext{
${ }^{29}$ WINZER. Das professionelle Tipp-Kick, p. 2-3.

${ }^{30}$ WINZER. Das professionelle Tipp-Kick, p. 2-3.

${ }^{31}$ WINZER. Das professionelle Tipp-Kick, p. 3.
} 
Associação Alemã de Tipp-Kick possui um livreto próprio com 17 páginas contendo regras e comentários detalhados sobre sua interpretação, por exemplo, como se deve executar um tiro de meta ou arremesso lateral, ou mesmo quais ações defensivas são permitidas na grande área, regulamentadas minuciosamente, que estão ausentes das regras na versão para o praticante "amador". 32

Por sua vez, para a prática profissional do Tipp-Kick, seja na categoria individual ou por equipe, é necessária a presença de um árbitro junto à mesa, pois a rapidez e a força na execução de chutes, frequentemente, dificultam a visão dos jogadores se a bola entrou na meta ou simplesmente bateu na trave ou no travessão, ou mesmo se entrou e saiu novamente. ${ }^{33}$

Outra questão é a de acesso à prática profissional do Tipp-Kick. Todo aquele que desejar praticar o jogo em nível profissional deve federar-se e treinar junto a uma das agremiações afiliadas à DTKV, a qual fornece informações em sua página na Internet sobre as diversas Ligas e clubes afiliados. Além disso, em geral, os próprios clubes possuem páginas próprias e divulgam suas normas para filiação.

Por fim, cabem algumas informações específicas sobre a DTKV, que, além de possuir estatuto próprio, se estrutura em quatro seções: a Seção Norte abrange as unidades federativas de Bremen, Hamburgo, Mecklenburg-Vorpommern, Niedersachsen e Schleswig-Holstein; a Seção Sul abrange os Estados de BadenWürttemberg, Bayern, Hessen, Rheinland-Pfalz e Saarland; a Seção Oeste integra apenas o Estado de Nordrhein-Westfalen; a Seção Leste abrange os Estados de Brandenburgo, Sachsen, Sachsen-Anhalt, Thüringen e a capital Berlim. Em cada uma dessas quatro Seções são realizadas, anualmente, assembleias regionais formadas por um grêmio da Liga e por representantes de todos os clubes filiados, sendo que todos os praticantes federados junto a cada clube possuem poder de voto. $\mathrm{Na}$ referida assembleia, é eleito um Dirigente da Seção, o qual tem por função coordenar os campeonatos da Liga em sua região e representá-la em nível nacional. ${ }^{34}$

A instância superior da DTKV é representada por um parlamento, o qual é composto pelos dirigentes das quatro Seções regionais e por cinco membros da

\footnotetext{
${ }^{32}$ WINZER. Das professionelle Tipp-Kick, p. 3.

${ }^{33}$ WINZER. Das professionelle Tipp-Kick, p. 3.

${ }^{34}$ WINZER. Das professionelle Tipp-Kick, p. 3.
} 
presidência da Associação. Esta é composta de um dirigente federal, de um diretor de torneios, de um tesoureiro, de um correspondente de imprensa e de um membro conselheiro. A eleição da presidência ocorre através do Parlamento, bienalmente. Os cinco membros desse grêmio elegem o Presidente da DTKV. 0 Parlamento se reúne uma vez por ano em assembleia, quando os dirigentes de Seção e os membros da Presidência apresentam seus relatórios e anunciam aos clubes os calendários dos torneios regionais, bem como do Campeonato Alemão e da Copa da Alemanha de Tipp-Kick. ${ }^{35}$

\section{TIPP-KICK: REGRAS E JOGABILIDADE}

Para esta seção, valer-nos-emos das informações disponíveis na página da Associação Alemã de Tipp-Kick (DTKV). ${ }^{36}$ Um fato curioso já está assinalado no título do texto: "A bola é angular e um jogo dura 10 minutos" (Der Ball ist eckig und ein Spiel dauert 10 Minuten). Trata-se de uma paródia da famosa frase do treinador da seleção alemã, campeã de 1954, o lendário Sepp Herberger, que teria dito a frase "A bola é redonda e um jogo dura 90 minutos" (Der Ball ist rund und ein Spiel dauert 90 Minuten $)^{37}$ ao ser indagado por um jornalista durante uma coletiva de imprensa sobre seus prognósticos para um jogo da seleção que seria realizado nos próximos dias.

Podemos pensar, de maneira ampla, na noção de "simulacro" proposta por Caillois para entendermos como, em certa medida, um jogo pode simular a jogabilidade de um outro jogo, no caso, o futebol. Sem dúvida, as regras de jogo, guardadas as devidas proporções, podem expressar tal simulação. Para essas conjecturas, tomamos por base a última versão do Caderno de Regras Oficiais da DTKV, que data de 01 de agosto de 2017. Ao todo, tal versão contém 16 regras, assim intituladas por tema:

Regra 1: Campo de jogo e mesa de torneio (Spielfeld und Turnierplatte) Regra 2: Peças de jogo (Spielfiguren)

Regra 3: Bola (Ball)

\footnotetext{
${ }^{35}$ WINZER. Das professionelle Tipp-Kick, p. 3.

${ }^{36}$ DER BALL IST ECKIG UND EIN SPIEL DAUERT 10 MINUTEN, s/p.

${ }^{37}$ SEPP HERBERGER, s/p.
} 


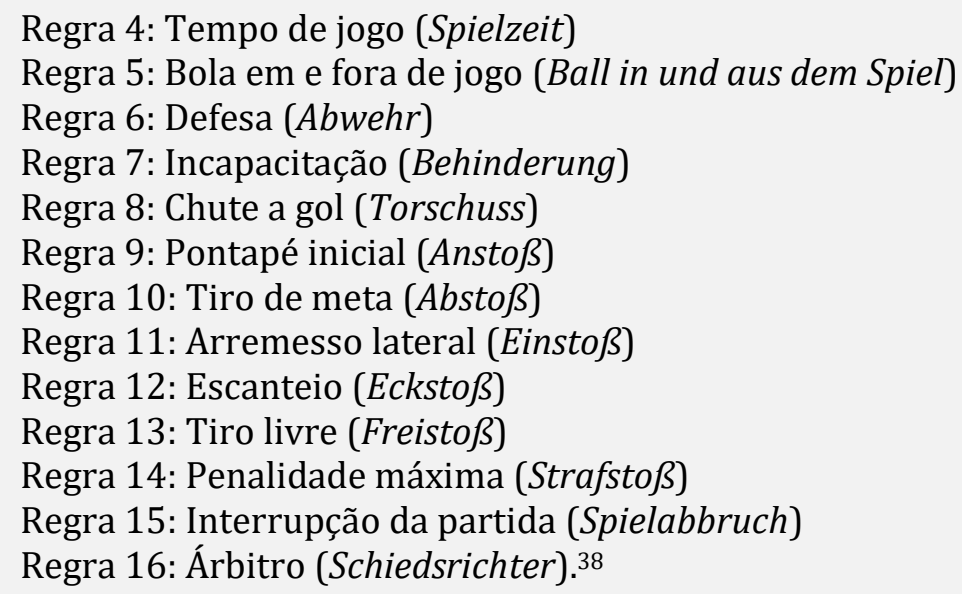

No âmbito deste artigo, apresentaremos, brevemente, apenas algumas dessas 16 regras, que nos permitam refletir sobre a jogabilidade do Tipp-Kick enquanto simulacro do futebol: Bola; Peças de jogo; Defesa; Tiro livre; Penalidade máxima; Tiro de meta. A regra 3, que indica as especificações da bola de jogo, determina que esta seja angular, com 12 lados, tenha duas cores, preta e branca, uma em cada metade. Antes do pontapé inicial, os dois jogadores escolhem uma das cores que valerá para o primeiro tempo de jogo. Após o intervalo, quando há troca de lado, as cores também são trocadas. Para que um determinado jogador dê prosseguimento à jogada, é necessário que a face superior da bola esteja na cor previamente escolhida antes do início da partida. Seu diâmetro é de $10 \mathrm{~mm}$, sendo que, embora a regra oficial determine as cores preta e branca, a firma Mieg comercializa também bolas nas cores amarela e vermelha. ${ }^{39}$ Para a jogabilidade, diferindo de outros jogos de futebol de mesa, como o Pebolim, o Subbuteo e o Futebol de Botão, a bola necessita conter a distinção de cores, além de ser angular de 12 cantos, o que lhe impede o rolamento.

Por sua vez, a regra 2 especifica quais são as peças ou figuras de jogo. Uma equipe consiste de um goleiro e, no máximo, cinco jogadores de linha diferentes. Todavia, durante a partida, apenas um dos jogadores de linha pode atuar em campo, sendo sua substituição permitida toda vez que uma determinada jogada for executada. Em geral, os cinco jogadores de linha diferem no formato da perna móvel, que possibilita determinados efeitos na

\footnotetext{
${ }^{38}$ TIPP-KICK SPIELREGELN, 01 ago. 2017, p. 2.

${ }^{39}$ TIPP-KICK SPIELREGELN, 01 ago. 2017, p. 6.
} 
bola, quando esta é acionada por pressão de botão posicionado na parte superior do jogador, que tem uma altura de $78 \mathrm{~mm} .{ }^{40}$

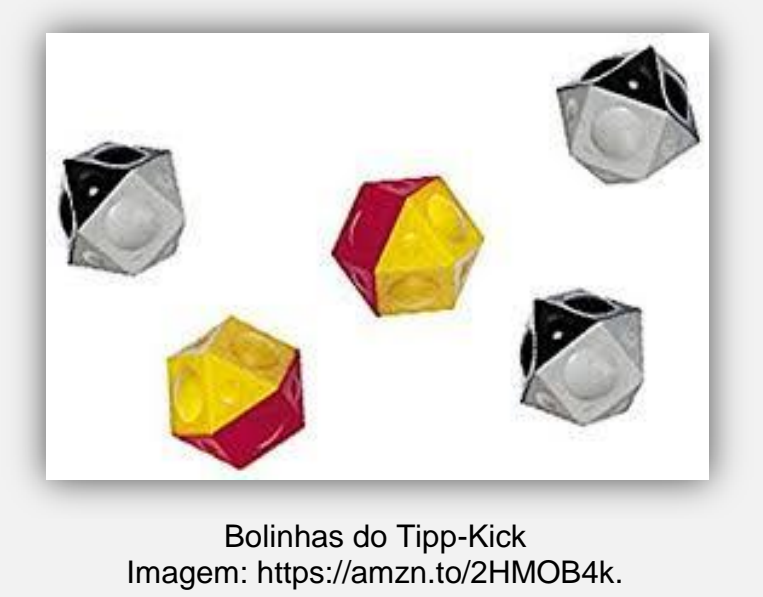

Aqui, em termos de simulacro do futebol, o Tipp-Kick apresenta um diferencial em relação a outros jogos de futebol de mesa, uma vez que uma equipe é composta apenas por um goleiro e um jogador de linha. Porém, a mobilidade da perna de chute é algo ausente nos demais jogos - nas figuras do Botão e do Subbuteo e do Pebolim, uma vez que neste se chuta a bola com a base do corpo, formada por pernas e pés juntos.

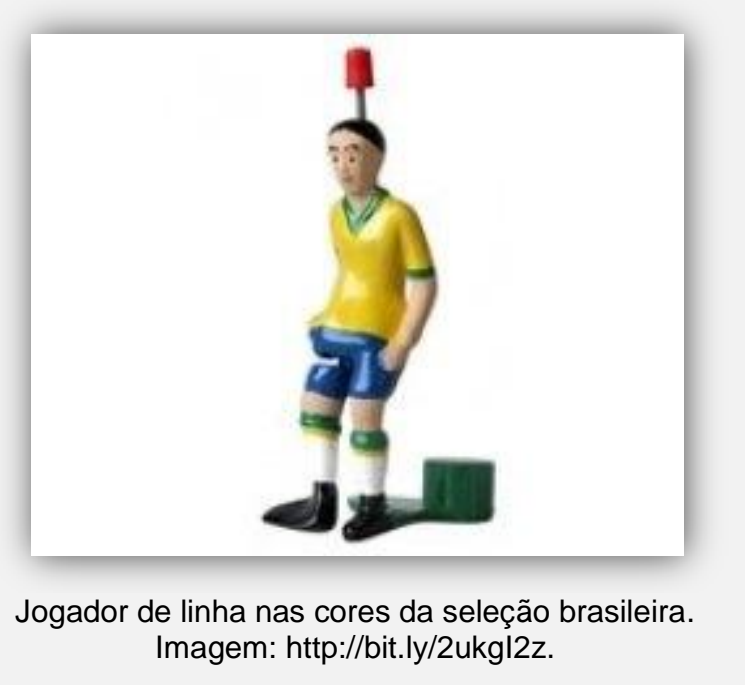

Já o goleiro deve conter uma haste de $70 \mathrm{~mm}$ de comprimento e pode ter acionamento de fábrica, para a direita e para a esquerda, de acordo com a pressão de botões em uma pequena caixa ligada à haste, cujo mecanismo interno permite

${ }^{40}$ TIPP-KICK SPIELREGELN, 01 ago. 2017, p. 4. 
tais movimentos do goleiro. Todavia, diferindo da versão de fábrica comercializada no mercado pela firma Mieg, de acordo com a regra oficial, o goleiro não pode ter movimentação para frente através de acionamento de botões. Assim, para jogos oficiais, os aficionados necessitam adquirir fabricados especificamente para esse fim, e fornecidos através da DTKV. ${ }^{41}$ Em termos de jogabilidade, o goleiro do TippKick oferece ao jogador muito mais possibilidades de movimentação que em outros jogos de futebol de mesa.

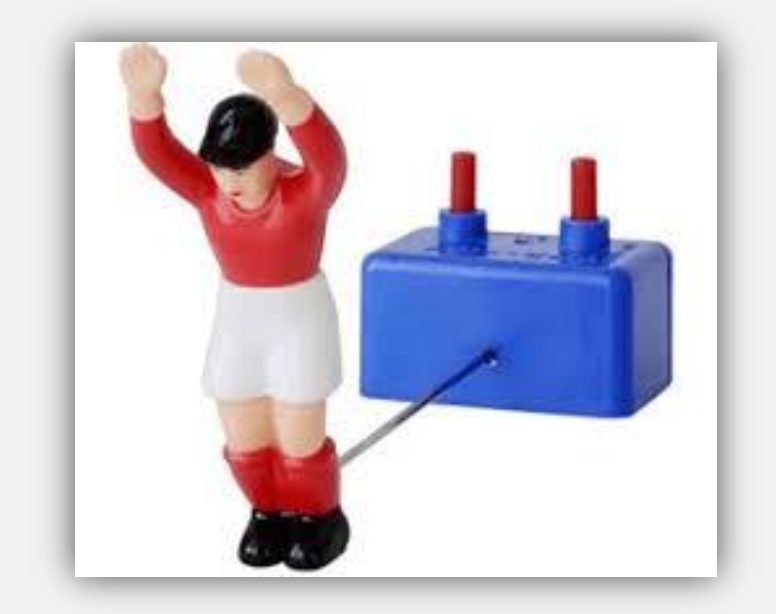

Goleiro do Tipp-Kick, com mecanismo de acionamento. Imagem: http://bit.ly/2Wh5Put.

Outra regra aqui destacada, a de número 6, versa sobre a defesa. Em ações defensivas, quando o adversário está com a posse de bola, o jogador de linha pode ser manualmente reposicionado em pé ou deitado de costas por aquele que está sendo atacado, pelo menos a uma distância da bola correspondente a duas vezes o comprimento do jogador de linha (em torno de $156 \mathrm{~mm}$ ), procurando, assim, dificultar a ação de ataque. Em caso de tiro livre, a distância da bola deve ser de três vezes o comprimento do jogador de linha (em torno de $234 \mathrm{~mm}$ ). Além disso, o jogador defensivo nunca deve ser posicionado na grande área. Quando ocorrer de a distância da bola até a linha da grande área ser inferior a duas vezes o comprimento do jogador de linha, o defensor pode ser posicionado sobre a linha da grande área. Porém, se a bola já se encontrar dentro da grande área, o defensor deve ser removido. ${ }^{42} \mathrm{~A}$ jogabilidade, de acordo com esta regra, basicamente, reside

\footnotetext{
${ }^{41}$ TIPP-KICK SPIELREGELN, 01 ago. 2017, p. 4.

42 TIPP-KICK SPIELREGELN, 01 ago. 2017, p. 8.
} 
em permitir uma movimentação de defesa que, assim como no futebol, dificulte a ação de ataque.

O conjunto de regras oficiais da DTKV também possui uma regra específica para determinação de tiro livre. A regra 13 regulamenta que, se o adversário desviar a bola com a mão, o braço ou outras partes do corpo, ocorrerá um tiro livre na posição em que foi cometida a infração. 0 defensor deverá posicionar seu jogador a uma distância da bola de, pelo menos, três vezes o comprimento de um jogador (em torno de $234 \mathrm{~mm}$ ). Outras ações são passíveis de serem punidas com tiro livre: mover a bola em desacordo com o que determina a regra 3, por exemplo, tocar a bola quando a posse for do adversário; bloquear a bola em uma forma que fira a regra 6, por exemplo, ao posicionar o jogador defensivo deitado lateralmente, e não de costas sobre o campo de jogo; executar um tiro de meta ou arremesso lateral de maneira incorreta; tocar a bola com um jogador de linha que não esteja em jogo. ${ }^{43}$ Assim como no futebol, além de determinar as várias modalidades de infração, as regras do Tipp-Kick preveem também a distância que um defensor deve estar da bola, por assim dizer, formando a barreira com apenas um jogador de linha.

Por sua vez, a penalidade máxima é assim determinada na regra 14 do Conjunto de Regras Oficiais da DTKV: Se uma infração for cometida na área, o tiro livre é executado como penalidade. Tal como acontece no futebol, o goleiro deve ser posicionado sobre a linha do gol, na posição vertical, e não pode ser movimentado antes do toque na bola pelo jogador do adversário. Caso essa regra seja ferida, a penalidade máxima deve ser cobrada novamente. Caso a penalidade máxima tenha sido cometida e assinalada pelo árbitro alguns segundos antes de encerrar o tempo de jogo, o adversário terá o direito de cobrar o pênalti. ${ }^{44} \mathrm{Em}$ princípio, esta é a regra que mais se aproxima do futebol, também semelhante às regras do Subbuteo e do Futebol de Botão que regulamentam a penalidade máxima.

Por fim, abordaremos brevemente uma última regra, a do tiro de meta. Trata-se da regra 10 do Conjunto de Regras Oficiais da DTKV. Na cobrança de tiro de meta, a bola deve ser posicionada na linha da pequena área. Ela deve ser

\footnotetext{
${ }^{43}$ TIPP-KICK SPIELREGELN, 01 ago. 2017, p. 14.

${ }^{44}$ TIPP-KICK SPIELREGELN, 01 ago. 2017, p. 15.
} 
colocada em jogo por um jogador de linha e lançada para além da linha da grande área, como ocorre no futebol. Caso esta não deixe o espaço da grande área na execução do tiro de meta, o adversário terá direito a um tiro livre da posição em que a bola parou. Além disso, um tiro de meta não pode resultar em gol. ${ }^{45}$ Mais uma vez, em termos de jogabilidade, essa regra simula o futebol, inclusive na possibilidade de se marcar um gol contra o adversário ao se executar um tiro de meta.

\section{TIPP-KICK: O JOGO E OUTRAS REPRESENTAÇÕES}

Em um breve artigo publicado no Frankfurter Allgemeine Zeitung em 18 de outubro de 2013, intitulado "Dante in Zink" ("Dante em miniatura de zinco"), o redator de esporte Daniel Meuren assim anuncia uma novidade no universo do Tipp-Kick:

Dante chega ao mercado de brinquedos como figura do Tipp-Kick. 0 jogador do Bayern é apropriado para ser representado devido a sua cabeleira inconfundível. Entretanto, na versão em zinco, o canhoto deverá chutar com a direita, como FAZ.NET descobriu com exclusividade após a figura sair da máquina de fundição. ${ }^{46}$

Na matéria, o articulista ressalta o fato de que o defensor do Bayern de Munique, Dante Bonfim Costa Santos, entraria para uma seleta galeria de atletas que teriam sido representados em miniatura, ou mesmo que teriam sido simplesmente engajados em campanhas publicitárias da firma Mieg, como, por exemplo, o centroavante Gerd Müller, o "Bombardeiro" (Bomber), artilheiro da seleção alemã e do Bayern de Munique nos anos 1960 e 1970. Ainda no início de sua carreira, Müller recebera 1.000 Marcos por direito de imagem para que fosse estampado na embalagem do Tipp-Kick. ${ }^{47}$

Todavia, Gerd Müller não teve a mesma oportunidade que Dante para ser representado como figura do Tipp-Kick. E os próprios fabricantes, por questões técnicas que demandariam modificações na padronização da máquina de fundição,

\footnotetext{
45 TIPP-KICK SPIELREGELN, 01 ago. 2017, p. 13-14.

${ }^{46}$ MEUREN. Dante in Zink, s/p. No original: „Dante kommt als Tipp-Kick-Figur auf den Spielzeugmarkt. Der Bayern-Spieler eignet sich wegen seiner unverkennbaren Haarpracht fürs gegossene Double. Allerdings muss der Linksfuß in Zink mit Rechts schießen, wie FAZ.NET nach Auswurf aus der Gussmaschine exklusiv enthüllt."

${ }^{47}$ MEUREN. Dante in Zink, s/p.
} 
decidiram representar a cabeleira de Dante como uma espécie de "peruca" de plástico, encaixada na cabeça das 10.000 miniaturas fundidas na primeira edição e pintadas com as cores da equipe bávara, com o número "4" e o nome "Dante" às costas. ${ }^{48}$ Assim como o craque brasileiro da NFL Anderson Varejão, ou mesmo o jogador belga Marouane Fellaini, Dante, à época, se destacava tanto por ótimas atuações em campo quanto por sua vasta cabeleira, aspecto aproveitado pela equipe de marketing da firma Mieg.

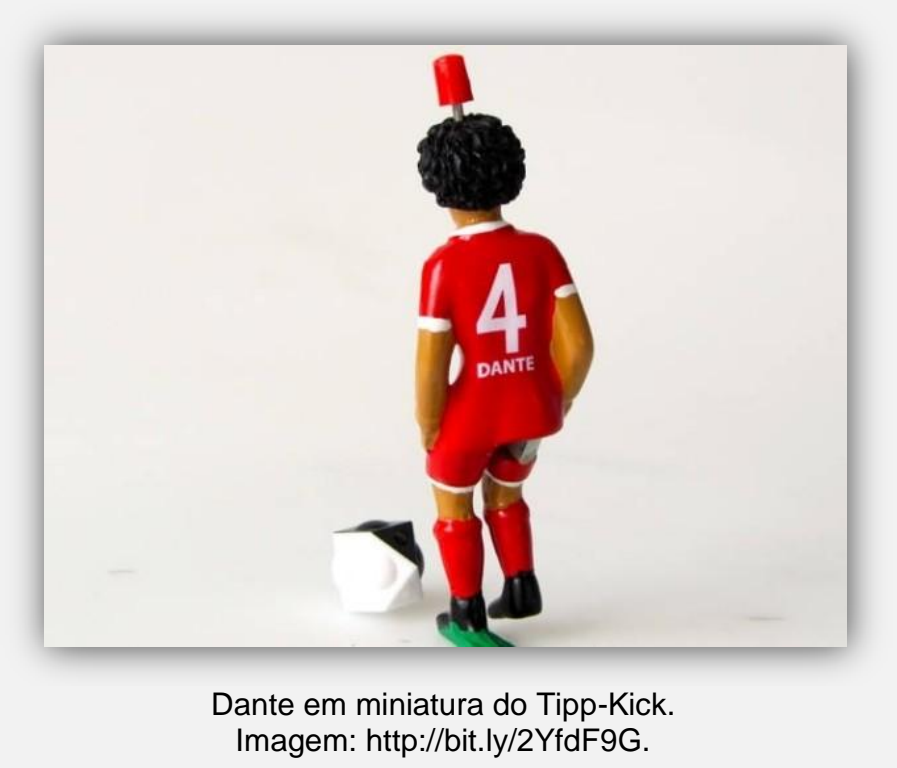

Antes de Dante, apenas um jogador da Bundesliga, o Campeonato Alemão, havia sido representado no final dos anos 1990 em miniatura do Tipp-Kick: o atacante Roy Präger, que atuava pelo VfL Wolfsburg. Para os fabricantes da Mieg, o fato de ser brasileiro tornava o zagueiro do Bayern um excelente elo de ligação com a Copa de 2014 no Brasil, que estava por vir, além de ser uma figura que desfrutava de ampla simpatia e fascinação atuando pela equipe bávara. 49

Não encontramos outras fontes na mídia que noticiassem sobre um possível sucesso de vendas da miniatura de Dante entre os torcedores do Bayern e os aficionados do Tipp-Kick em geral. Na matéria de 2013, o jogador brasileiro, que atuava desde abril de 2012 e deixaria a equipe bávara em agosto de 2015, se encontrava no auge. Segundo Daniel Meuren, os fabricantes cogitavam até mesmo, pela primeira vez na história da firma Mieg, produzir miniaturas com a perna

\footnotetext{
${ }^{48}$ MEUREN. Dante in Zink, s/p.

${ }^{49}$ MEUREN. Dante in Zink, s/p.
} 
esquerda móvel, fazendo jus ao defensor canhoto, caso a procura pela figura de Dante fosse grande. E havia a intenção de que a miniatura fosse pintada também nas cores da seleção brasileira. ${ }^{50}$ Jochen Mieg chegou a declarar o seguinte em entrevista concedida a Daniel Meuren: "Esperamos que Dante não tenha problema em ter de chutar com a direita na nossa versão em miniatura, porque ele, como profissional, é praticamente ambidestro. [...] Mas, talvez, Dante será o primeiro canhoto na história da nossa empresa'". ${ }^{51}$

Podemos apenas inferir que o sucesso de mercado da miniatura ficou pelo caminho, assim como o sucesso do representado nas equipes do Bayern e da seleção canarinho, após o histórico vexame do 7x1 em 08 de julho de 2014, o Mineiraço, partida em que Dante substituíra o capitão Thiago Silva, suspenso, e fora um dos defensores brasileiros colocados na roda pelo meio de campo e ataque da seleção alemã, entre outros, por seus companheiros de Bayern à época: Toni Kroos, Bastian Schweinsteiger e Thomas Müller, além do lateral direito Philipp Lahm, do zagueiro Jérôme Boateng e do goleiro Manuel Neuer, todos titulares naquela partida.

Fato é que Dante se destacara pelo Bayern ao integrar a equipe que conquistou a Tríplice Coroa em 2013 (Campeonato Alemão, Copa da Alemanha e Champions League). Após o Mineiraço, não voltou a ser convocado para a seleção brasileira. E logo após retornar da Copa, não pode evitar as gozações pelo vexame, inclusive por alguns companheiros de Bayern, como Thomas Müller. Com a chegada do treinador Pepe Guardiola, o zagueiro decidiu deixar a equipe e se transferiu para o clube alemão VfL Wolfsburg. Na temporada 2016/17, Dante foi para o clube francês OGC Nizza. Aliás, a representação de Dante como miniatura do Tipp-Kick não deixa de ser parte do simulacro do futebol, com suas figuras famosas. Talvez isso tenha ocorrido raramente na história da Mieg por questões derivadas da própria jogabilidade, ao contar com apenas um jogador de linha

\footnotetext{
${ }^{50}$ MEUREN. Dante in Zink, s/p.

${ }^{51}$ MIEG apud MEUREN. Dante im Zink, s/p. No orginal: „Dante hat hoffentlich kein Problem damit, dass er bei uns bislang nur mit dem rechten Fuß schießen kann, weil er als Profi ja ohnehin fast beidfüßig ist. [...] Aber vielleicht wird Dante ja noch der erste Linksfuß in unserer Unternehmensgeschichte."
} 
dentro de campo, por equipe, e ao representar a figura de modo impessoal, distinta apenas pelas cores do uniforme em relação ao jogador de linha do adversário.

Por sua vez, outra matéria sobre representações de jogadores em formato miniatura do Tipp-Kick pela Firma Mieg, publicada em 22 de fevereiro de 2010 pelo jornal Frankfurter Rundschau, chamou à atenção: “Tippse mit Knöpfchen. Die erste Tipp-Kick-Frau" ("Secretária com botãozinho: a primeira mulher do TippKick"). Não obstante o título, um tanto quanto irônico ou mesmo pejorativo, evocado pelo termo "Tippse" quando empregado em expressões coloquiais, que significa escrevente, linotipista ou secretária, a jornalista Ute Diefenbach noticia a novidade da criação do Tipp-Kick com figuras femininas.

Além disso, a matéria é ilustrada por uma fotografia de autoria de Georg Urbik, com a seguinte legenda: "A primeira lady Tipp-Kick - sugestões alternativas da redação do Frankfurter Rundschau (da esquerda para a direita: Naomi Campbell, Angela Merkel, miniatura feminina do Tipp-Kick)". ${ }^{2}$ Portanto, a modelo e atriz norte-americana e a chanceler alemã seriam as "sugestões" do jornal para a miniatura feminina. E a matéria apresenta o seguinte lead: "Discussão sobre curvas no futebol alemão: A primeira mulher do Tipp-Kick é um golaço ou um gol contra?"53

Por sua vez, Ute Diefenbach assim descreve a figura feminina do Tipp-Kick:

Ela é, por assim dizer, a mulher da ofensiva, embora não tenha feito nada de errado até agora. Não é sequer uma ofensiva, porque no campo de futebol ela não pode sequer correr. Com calções pretos, meias e camisa branca de manga comprida, ela está preparada para entrar em ação. 0 longo cabelo castanho na altura dos ombros é penteado a partir do rosto, de modo que a visão da meta estaria livre. Seus lábios finos têm um toque de cor vermelha, mas sutil. Presumivelmente, ela traja um sutiã esportivo, que fica um pouco apertado demais e, com isso, achata o tórax desconfortavelmente. Talvez ela simplesmente não tenha seios tão volumosos. ${ }^{54}$

\footnotetext{
52 DIEFENBACH. Tippse mit Knöpfchen. Die erste Tipp-Kick-Frau, s/p. No original: „Die echte Tipp-Kick-Lady - und Alternativ-Vorschläge der FR-Redaktion (v.l.: Cindy Crawford [sic], Angela Merkel, Tipp-Kick-Frau).“

${ }^{53}$ DIEFENBACH. Tippse mit Knöpfchen. Die erste Tipp-Kick-Frau, s/p. No original: „Kurvendiskussion im deutschen Fußball: Ist die erste Tipp-Kick-Frau ein Volltreffer oder ein Eigentor?"

${ }^{54}$ DIEFENBACH. Tippse mit Knöpfchen. Die erste Tipp-Kick-Frau, s/p. No original: „Sie ist sozusagen die Frau des Anstoßes, obwohl sie sich bisher nichts zuschulden kommen ließ. Schon gar keinen Anstoß, denn auf dem Fußballfeld darf sie noch gar nicht auflaufen. Mit schwarzen Shorts, Stutzen und langärmeligem weißen Trikot ist sie für ihren Einsatz allerdings gerüstet. Die schulterlangen braunen Haare sind aus dem Gesicht gekämmt, der Blick aufs Tor
} 
A figura, pintada nas cores da seleção alemã, é avaliada pela articulista em seus contornos físicos e supostos traços de feminilidade. 0 tom irônico parece marcar, justamente, uma crítica à ideia de se criar uma versão feminina para a miniatura do Tipp-Kick, ou melhor, a discussão que tal ideia gera:

Não, ela não é indescritivelmente feminina. Ampliada várias vezes, seu rosto até ganha traços grotescos, assim como seus colegas do sexo masculino. No entanto, ela é uma estrela, porque deve ser a primeira mulher no Tipp-Kick, jogo tradicionalmente masculino, depois de 85 anos. Ela é assim como o Beto para Barbie - só que em relação inversa. Ela é a Birgit para o Toni, a Steffi para o Philipp. ${ }^{55}$

Em sua matéria, Ute Diefenbach argumenta que, de alguma forma, bastaria uma mulher estar em evidência para que surgissem questionamentos do tipo: "Pode isso? Permitem isso? E, afinal, com que aparência?"56 Seria como se a miniatura feminina do principal jogo alemão que simula o futebol assumisse os preconceitos com relação à mulher e o próprio ambiente do futebol, justamente num país em que o futebol é a principal modalidade, e em que o futebol de mulheres não só é praticado em alto nível, como também apresenta um nível de organização superior àquele de outros países, como, por exemplo, o Brasil, que se autodenomina de "país do futebol". Criada à imagem e semelhança do modelo masculino, com apenas algumas distinções, a miniatura feminina do Tipp-Kick dividiria as opiniões, algumas marcadamente misóginas, como a do presidente da Associação Alemã de Tipp-Kick (DTKV), Sebastian Krapoth, que teria declarado:

wäre frei. Ihre schmalen Lippen weisen einen Hauch von Farbe auf - rot, aber dezent. Vermutlich trägt sie einen Sport-BH, der etwas zu stramm sitzt und den Oberkörper daher ungünstig verflacht. Vielleicht hat sie aber auch einfach nicht so viel Holz vor der Hütte."

55 DIEFENBACH. Tippse mit Knöpfchen. Die erste Tipp-Kick-Frau, s/p. No original: „Nein, unbeschreiblich weiblich ist sie nicht. Mehrfach vergrößert bekommt ihr Gesicht sogar fratzenhafte Züge, genau wie das ihrer männlichen Kollegen. Dennoch ist sie ein Star, denn sie soll nach 85 Jahren die erste Frau im traditionell männlichen Tipp-Kick-Spiel sein. Sie verhält sich also wie Ken zu Barbie - nur umgekehrt. Sie ist die Birgit für den Toni, die Steffi für Philipp.“ ${ }^{56}$ DIEFENBACH. Tippse mit Knöpfchen. Die erste Tipp-Kick-Frau, s/p. No original: „Kann die das? Darf die das? Und - wie sieht die überhaupt aus?" 
“"Ela [i.e., a miniatura feminina] é provavelmente um pouco mais larga na altura do peito e ocupa mais espaço na área de defesa'”. ${ }^{57}$

Além disso, dentre os mais de 800 jogadores associados à DTKV, registrados em 2010, apenas 20 eram mulheres, mas nenhuma disputava a primeira liga do Campeonato Alemão de Tipp Kick. Sobre o fato de a miniatura feminina possuir poucas diferenças físicas em relação à versão masculina, o fabricante Jochen Mieg foi taxativo: "O Tipp-Kick não deve ser sexista"'.58 Para um dos herdeiros proprietários da Firma Mieg, a figura representaria uma jovem "atraente, mas esportiva", que, assim, como a versão masculina, não receberia um nome em especial.

Como em outras oportunidades, mais uma vez, a firma Mieg procurou responder à demanda de mercado, aproveitando um evento em especial para difundir a miniatura feminina do Tipp-Kick: a Copa do Mundo de Futebol Feminino, que seria realizada em 2011, na Alemanha. Primeiramente, em setembro de 2010, foi lançada no mercado a primeira edição com 10.000 unidades, nas cores do uniforme da seleção alemã, e também da seleção brasileira.

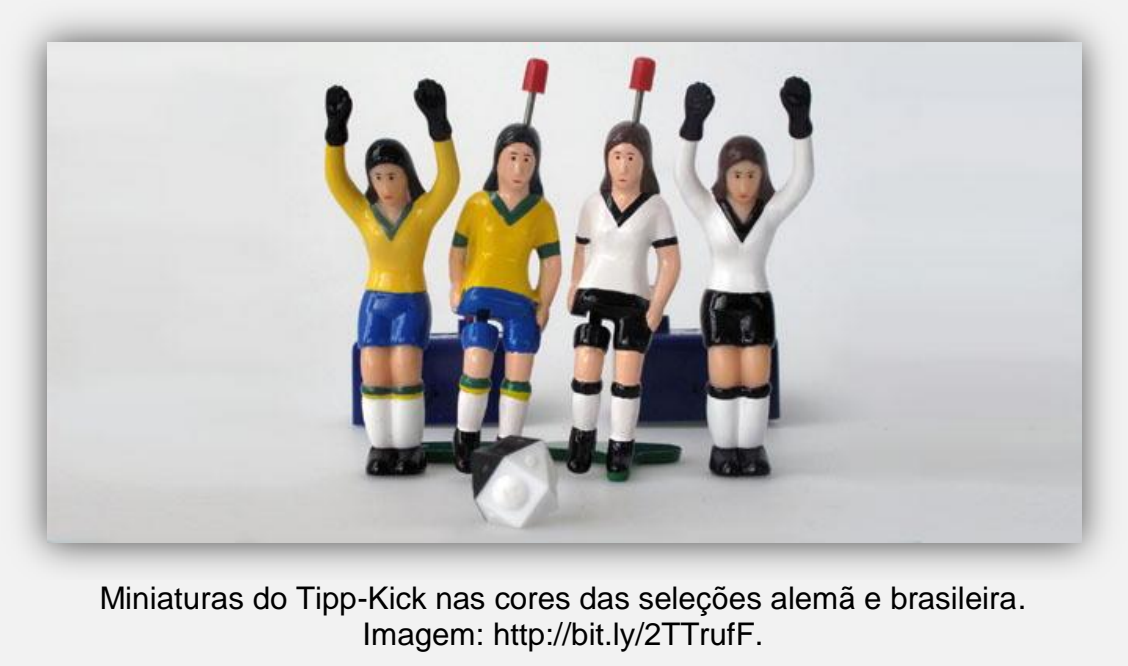

Pouco menos de um ano antes, a revista Spiegel Online havia noticiado, brevemente, o projeto da firma Mieg em lançar a versão feminina do Tipp-Kick:

\footnotetext{
${ }^{57}$ KRAPOTH apud DIEFENBACH. Tippse mit Knöpfchen. Die erste Tipp-Kick-Frau, s/p. No original: „Sie ist im Brustbereich wohl doch etwas breiter und nimmt im Abwehrbereich mehr Fläche ein."

${ }^{58}$ MIEG apud DIEFENBACH. Tippse mit Knöpfchen. Die erste Tipp-Kick-Frau, s/p. No original: "Tipp-Kick darf nicht sexistisch sein.“"
} 
“Tipp-Kick wird weiblich" ("Tipp-Kick se tornará feminino"). Em nota inominada, é anunciada a novidade da Mieg, que desde 1924 seria "assunto para homens" (Männersache), e que estaria se emancipando com sua nova criação: "O futebol de mulheres conquista o jogo Tipp-Kick: as pequenas miniaturas de metal, de acordo com o fabricante, também deverão ter sua variante feminina - entretanto, com limitações". 59

Além de reiterar o crescente interesse pelo futebol de mulheres no país, em especial pelas conquistas da seleção alemã e com a proximidade do Mundial de 2011, a nota também menciona a questão da aparência da versão feminina do Tipp-Kick: "A figura esportiva deve estar em primeiro plano", segundo declaração de Mathias Mieg. ${ }^{60}$ Entretanto, naquele momento, ainda era uma incógnita se a DTKV introduziria no Campeonato Alemão a nova figura do Tipp-Kick.

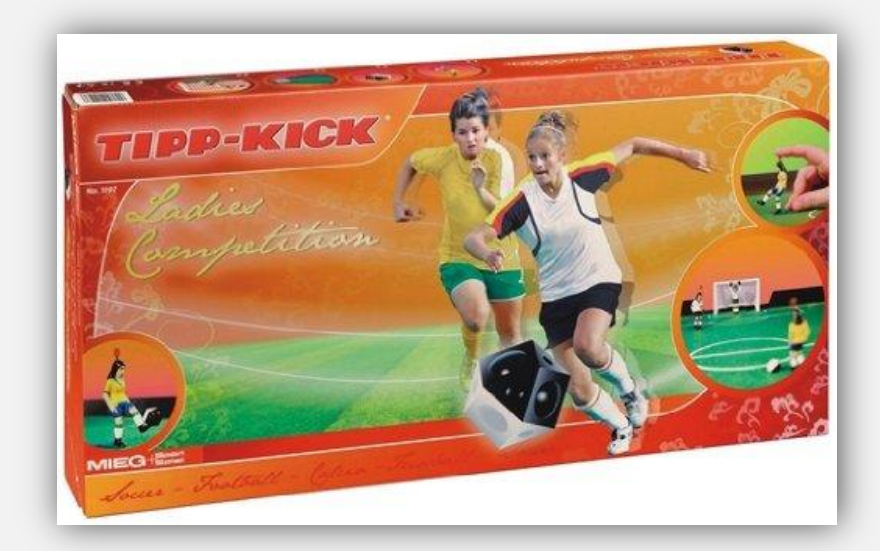

Embalagem do Tipp-Kick para a versão do futebol de mulheres. Imagem: https://amzn.to/2OjRf2o.

Entretanto, como os próprios fabricantes da Mieg reconheceram, levou um tempo até que o futebol de mulheres passasse a ser referência e gerasse demanda por produtos, inclusive para estratégias de marketing por parte da empresa, uma vez que fora proibido na Alemanha entre 1955 e 1970, e somente em 1982 a seleção alemã realizaria a sua primeira partida oficial, contra a seleção da Suíça, em que vencera o jogo por 5x1. Hoje, a seleção alemã possui um ranking invejável, com dois títulos mundiais $(2003 ; 2007)$, oito títulos europeus $(1989 ; 1991 ; 1995$;

59 TIPP-KICK WIRD WEIBLICH, s/p. No original:

„Der Frauenfußball erobert das Tischspiel Tipp-Kick: Die kleinen Metallfiguren soll es nun laut Hersteller auch in einer weiblichen Variante geben - allerdings mit gewissen Einschränkungen."

${ }^{60}$ MIEG apud TIPP-KICK WIRD WEIBLICH, s/p. No original:

„Die sportliche Figur steht im Vordergrund“. 
1997; 2001; 2005; 2009; 2013), três medalhas de bronze (2000, 2004 e 2008) e uma medalha de ouro nos Jogos Olímpicos (2016).

\section{TIPP-KICK, UM JOGO COMO SIMULACRO DO FUTEBOL - À GUISA DE CONCLUSÃO}

Se, conforme proposto por Johan Huizinga, podemos considerar o jogo em geral uma "forma significante",61 resta-nos a indagação: enquanto "forma significante", como poderíamos interpretar o Tipp-Kick? Enquanto modalidade de jogos de mesa que simulam o futebol - juntamente com o Pebolim, o Subbuteo e o Futebol de Botão, entre outros -, suas especificidades derivam de sua jogabilidade, sempre atrelada a aperfeiçoamentos que o jogo sofrera desde 1921 em seus componentes, de suas regras, e de determinadas representações, como o caso dos jogadores Roy Präger e Dante, e também da figura feminina representando o futebol de mulheres.

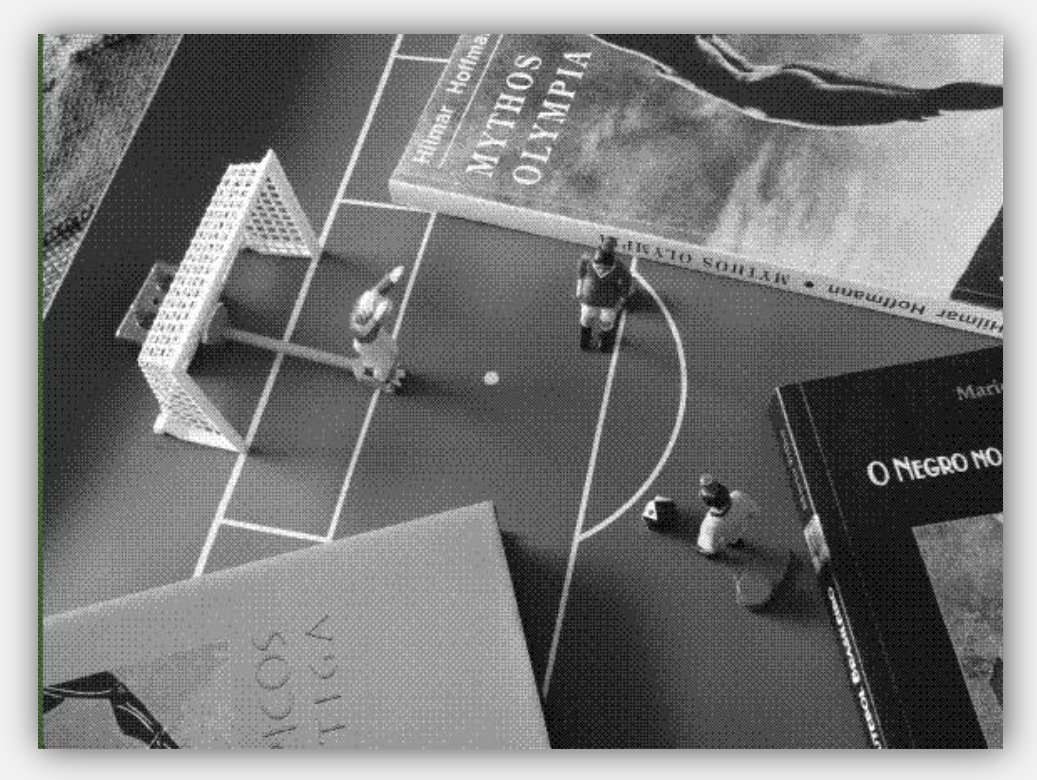

Tipp-Kick, um jogo alemão. Imagem: Elcio Cornelsen.

Por sua vez, se o jogo em geral é "uma evasão da vida 'real' para uma esfera temporária de atividade com orientação própria", 62 o Tipp-Kick, ao ser simulacro de um simulacro - o jogo de futebol propriamente dito, representaria uma dupla evasão da vida "real". Enquanto "simulacro", 63 nos termos propostos por Roger

\footnotetext{
${ }^{61}$ HUIZINGA. Homo Ludens, p. 6.

62 HUIZINGA. Homo Ludens, p. 11.

${ }^{63}$ CAILLOIS. Os jogos e os homens, p. 42.
} 
Caillois, o prazer por representar algo outro existente estaria na base da própria criação do jogo e de sua jogabilidade, sendo esta em maior ou menor grau garantida por regras e por condições derivadas de sua própria materialidade. Para os amantes do futebol, sem dúvida, mais um de seus diversos simulacros, mas que ainda permanece pouco conhecido no Brasil.

\section{REFERÊNCIAS}

CAILLOIS, Roger. Os jogos e os homens. Trad J. G. Palha. Lisboa: Cotovia, 1990. CORNELSEN, Elcio Loureiro. O futebol e seus simulacros no reino da ludicidade - Subbuteo, História(s) do Sport, UFRJ, s/p, 18 dez. 2018.

CORNELSEN, Elcio Loureiro. Sentimento e política no futebol alemão construções da "nação" em 1990 e 2006. História: Questões \& Debates, Curitiba, n. 57, p. 73-99, jul./dez. 2012.

DER BALL IST ECKIG UND EIN SPIEL DAUERT 10 MINUTEN, s/p. Disponível em: https://dtkv.info/tipp-kick/spielregeln. Acesso em: 01 dez. 2018.

DIE WM RETTET TIPP-KICK. Disponível em: http://bit.ly/2YcfEeS. Acesso em: 01 dez. 2018.

DIEFENBACH, Ute. Tippse mit Knöpfchen. Die erste Tipp-Kick-Frau. Frankfurter Rundschau, 22 fev. 2010. Disponível em: http://bit.ly/2OfN3ki. Acesso em: 01 dez. 2018.

GOMES, Eduardo de Souza. Pebolim, Totó, Fla-Flu ou Pacau? Um breve histórico do campo esportivo no Brasil, s/p. Ludopédio, n. 115, v. 5, 07 jan. 2019.

HÖFER, Katrin; HESSE, Peter. Das große Tipp-Kick-Buch: Geschichte, Regeln, Technik, Zubehör, Anekdoten. Berlin: Humboldt, 2008.

HUIZINGA, Johan. Homo ludens: o jogo como elemento da cultura. 6‥ ed., trad. João Paulo Monteiro, São Paulo: Perspectiva, 2010. [estudos; 4]

MEINERT, Peer. Tipp-Kick: Kult aus Schwenningen. Schwäbische Zeitung, 27 apr 2018. Disponível em: http://bit.ly/2HMFsbH. Acesso em: 01 dez. 2018.

MEUNER, Daniel. Dante in Zink. Frankfurter Allgemeine Zeitung, 18 out. 2013. Disponível em: http://bit.ly/2TN657E. Acesso em: 01 dez. 2018. 
ROLIM, Bruno. Futebol de Mesa: brincadeira que virou esporte. Jornal Comunicação, s/p, 28 fev. 2008. Disponível em: http://bit.ly/2OhwHHW; acesso em: 01 dez. 2018.

SEITH, Anne. Tipp-Kick-Kult: WM auf dem Küchentisch. Spiegel Online, 24 maio 2006. Disponível em: http://bit.ly/2HLRwKv. Acesso em: 01 dez. 2018.

SEPP HERBERGER, s/p. Disponível em: http://bit.ly/2TOvMF0. Acesso em: 01 dez. 2018.

TIPP-KICK SPIELREGELN, 01 ago. 2017, p. 2. Disponível em: http://bit.ly/2TQ8yy5. Acesso em: 01 dez. 2018.

TIPP-KICK WIRD WEIBLICH. Spiegel Online, 21 dez. 2009. Disponível em: http://bit.ly/2TTbl9SI. Acesso em: 01 dez. 2018.

WINZER, Simon. Das professionelle Tipp-Kick: Ein Spiel im Spannungsfeld zwischen Hobby und sportlicher Anerkennung. Zürich: Open Publishing, 2012. 